\title{
Seismic design of a super-tall building: Indonesian experience
}

\author{
Davy Sukamta ${ }^{1}$, Nick Alexander ${ }^{2}$ \\ ${ }^{1}$ Founder and Principal, Davy Sukamta \& Partners - Structural Engineers, Jakarta \\ ${ }^{2}$ Partner, Davy Sukamta \& Partners - Structural Engineers, Jakarta
}

\begin{abstract}
This paper summarizes the structural concept and design of the twin 303-meter high "Indonesia1" supertall building currently under construction in Jakarta. The first tower is a 63-story office building, and the second is 59-story, on top of the seven-level basement structure. The lateral resisting system of the towers is RC core-wall and outrigger, and composite floor system - with concrete slab, metal deck, and steel beams - is used for the gravity resisting system. Since the lateral system is outside the scope of the prescriptive system in the Indonesian Seismic Design Code, Modal Pushover Analysis (MPA) combined with Non-linear Response History Analysis (NLRHA) had demonstrated acceptability to the Jakarta building department and its peer review panel. Some challenges in conducting Performance-based Seismic Design (PBSD) are highlighted. In order to speed up construction, which is a critical factor in supertall building construction, erection columns are installed in the RC columns and CSPCM (Core Structure Preceding Construction Method) is applied. Consistently, the design must account for the associated construction sequence.
\end{abstract}

\section{Preface}

Indonesia-1 project is a mixed-use development in central Jakarta. It consists of two towers; the North Tower is a 63-story office building while the South Tower is a 59-story office and apartment building. Both towers have the same height, 303 meters, and sit on a 7level basement structure. This development has a total constructed floor area of around 306,000 square meters. The developer is China Sonangol Media Nusantara.

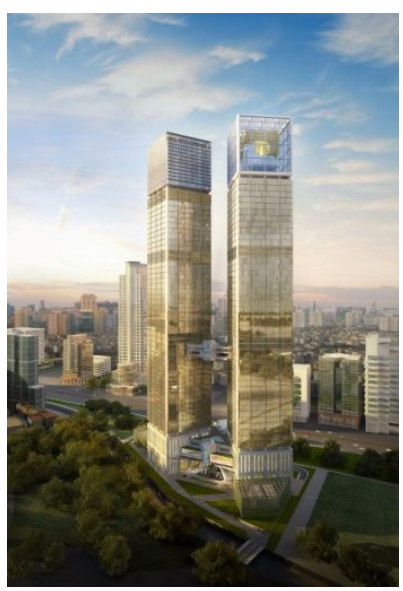

Fig 1. Rendering of Indonesia-1 project

The two super-tall towers use composite construction. The lateral resisting system is coupled with RC core-wall with outrigger. The gravity resisting system is provided by composite RC slab on metal deck on steel beams with RC columns. In order to speed up the construction, steel erection columns are provided, and Core Structure Preceding Construction Method (CSPCM) with unequal height synchronous rise is adopted. The foundation system is post-grouted highcapacity bored-pile. The deep basement with a 25-meter excavation is currently the deepest one constructed in Jakarta. Figure 1 shows the rendering of the two towers with sky bridges. At the top of South tower, above the ten floors of apartment units, is the crown structure. Figure 2 shows the structural scheme of the towers. The design and supervision of this development is performed by Davy Sukamta \& Partners, an Indonesian engineering firm based in Jakarta. The services cover the geotechnical, foundation, and super-structure design of the project for the entire design phase from conceptual to working drawings and specifications. For quality control of the foundation and structural work, full-time resident engineers have been assigned, which is not a normal practice in Indonesia but required by the foreign client for a project of this scale.

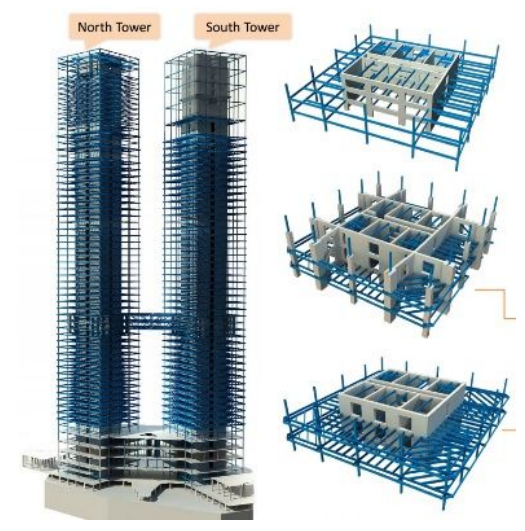

Fig 2. Structural System of Indonesia-1

\footnotetext{
* Corresponding author: davy@davysukamta.com
} 
The design takes constructability aspects into account from the very early phase, as well as the availability of local materials and work culture in Indonesia. Concrete with $70 \mathrm{MPa}$ grade is used, which is the highest ever applied to cast-in-situ building structure in Indonesia. Composite construction is adopted to take advantage of the stiffness of the RC core-wall and the high strength to weight ratio of steel structure and to provide a faster construction schedule. High capacity post grouted bored-pile helps in reducing the construction time by three months.

\section{Gravity resisting system}

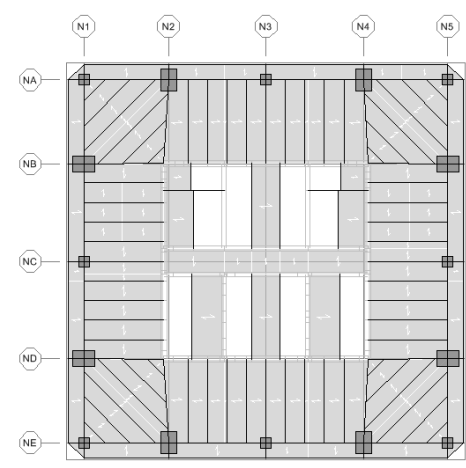

Fig 3. Plan of typical floor
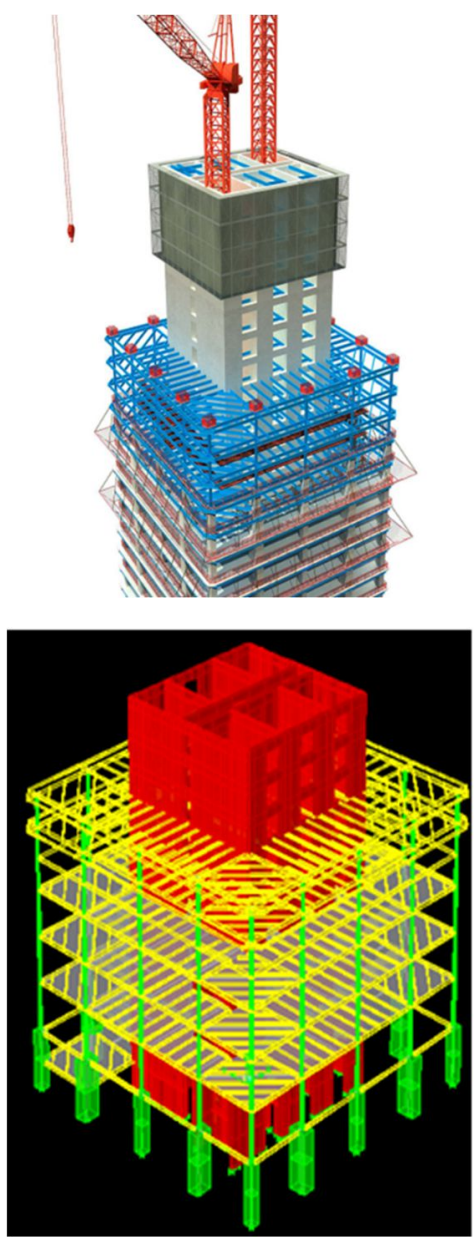

Fig 4. CSPCM with unequal height synchronous rise
For the Indonesia-1 project, a study has been conducted for the gravity system during the conceptual design phase. Three alternatives have been considered: 1 . Steel beam with composite metal deck, and composite column; 2.RC beams with composite column and RC slab; 3.RC beam with RC column, and $\mathrm{RC}$ slab. Alternative 1 has the advantage of 6-7 months faster construction time and huge saving in foundation cost due to reduced weight, but the cost of the floor system material itself is more expensive than the conventional RC. Taking all factors into consideration, including the monthly expenses of the contractor's overhead and engineering fees, alternative 1 turned out to be the most cost-effective solution. The typical floor framing is presented in Figure 3 below. Figure 4 shows the concept of the construction sequence and the related analysis model. The construction cycle per floor is expected to be 4-5 days using this CSPCM.

\section{Lateral resisting system}

The lateral resisting system for the two towers is RC coupled core-wall with two-story outrigger beams/RC panels and RC outrigger columns (figure 5). The central core wall dimension is $25 \mathrm{~m}$ by $23 \mathrm{~m}$, and the maximum thickness of the core wall is $800 \mathrm{~mm}$ at the bottom of the building. Outrigger system is introduced at the lower refuge floor $\left(20^{\text {th }}\right.$ floor). Outrigger system ties the corewall and the outrigger columns and transfer the bending moment in the core-wall to coupled axial forces in the outrigger columns. This system provides the required stiffness for the slender structure with efficient use of material and reduces the overturning moment in the core-wall. It uses the whole width of the building to resist the overturning moment due to lateral load, instead of just the width of the core-wall if no outrigger beams are installed. However, this system is not in the prescriptive list of Indonesian Seismic Resistant Design Code SNI 1726:2012. A performance-based approach is then required to demonstrate the structural behavior, and all structural components meet the acceptance criteria. Besides meeting the seismic design criteria, the lateral resisting system must fulfill the wind design requirements as well, including the human response to motion. The inter-story drift must be within acceptable limits to avoid damage to non-structural components.

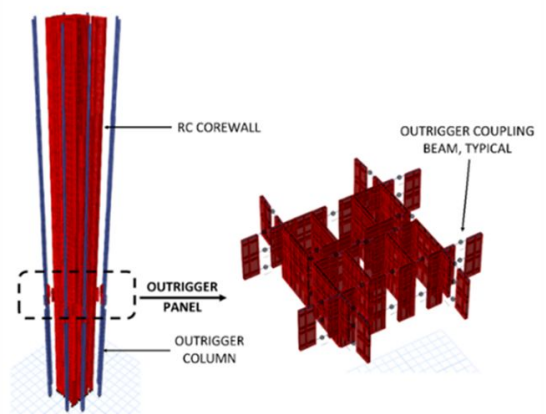

Fig 5. Seismic lateral force-resisting system: reinforced concrete core-wall with outrigger system, consisting of outrigger panels and coupling beams as seismic fuse. 


\section{Pbsd of indonesia-1 north tower}

Currently, two types of analysis are commonly used in Performance-Based Seismic Design (PBSD), namely Nonlinear Response History Analysis (NLRHA) and Nonlinear Static Procedure (NSP). The NLRHA is considered to be the most suitable since it is generally believed to provide accurate results for tall buildings. However, considering the rigorous nature of the process involved, including analysis time required, this procedure can be impractical to use. In addition, developing a suite of ground motion inputs for analysis can be challenging due to the use of UHS as a target spectrum and due to limited availability of strong motion records that can reasonably match with the target spectrum, particularly in Indonesia. NSP is the most practical nonlinear analysis procedure available; however, it is not appropriate to be used for tall buildings where higher modes effects dominate the structural response.

Due to the limitations NLRHA and NSP, an alternative analysis procedure that can retain the practicality of its use while providing reasonably accurate structural response estimate is very beneficial. Based on analytical study and research, Modal Pushover Analysis (MPA) is an alternative procedure that can practically overcome the limitations of NLRHA and NSP procedure, as previously described (Chopra). MPA is basically an enhancement version of NSP with the infusion of the Response Spectrum Analysis (RSA) principle. Combining the RSA principle with the conventional (1-mode) NSP significantly improves the accuracy of MPA results by accounting higher mode effects in estimating structural response. The analysis procedure used for PBSD of Indonesia-1 North Tower is MPA accompanied by NLRHA results from a few selected ground motion pairs to verify the accuracy of MPA results.

The following discussion provides a description of the structural system and configuration, modeling, and MPA results.

\section{Performance objective}

Established target performance objective for Indonesia1 North Tower is shown in table 1. In order to satisfy the target performance objective, each structural action from every structural element is classified as either deformation-controlled for structural actions exhibiting ductile behavior or force-controlled for other actions with brittle failure mechanism.

Table 1. Performance Objectives

\begin{tabular}{l|l} 
Level of earthquake & $\begin{array}{l}\text { Earthquake performance } \\
\text { objectives }\end{array}$ \\
\hline $\begin{array}{l}\text { Design-based earthquake (DBE): 475-year return period with 5\% } \\
\text { damping based on SNI 03-1726: } 2012\end{array}$ & Life safety \\
\hline $\begin{array}{l}\text { Maximum considered earthquake (MCE } \mathrm{R}): 2475 \text {-year return period with } \\
\text { 5\% damping (SNI 03-1726: 2012) }\end{array}$ & Collapse prevention \\
\hline
\end{tabular}

\section{Modal characteristics}

Modal characteristics of Indonesia-1 North Tower are presented in Figures 6 and 7. Figure 6 shows the planview building deformation at the roof level for various building modes. For the first triplet, mode 1 and 2 are translational modes, while mode 3 is a torsional mode. For the second and third triplets, modal coupling between X-direction translation and torsional DOF can be observed. Figure 7 shows the variation of modal shapes along the building height.

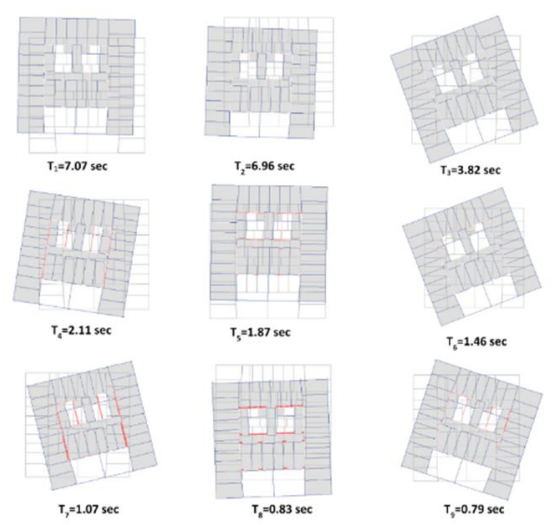

Fig 6. Roof floor plan-view modal deformations 


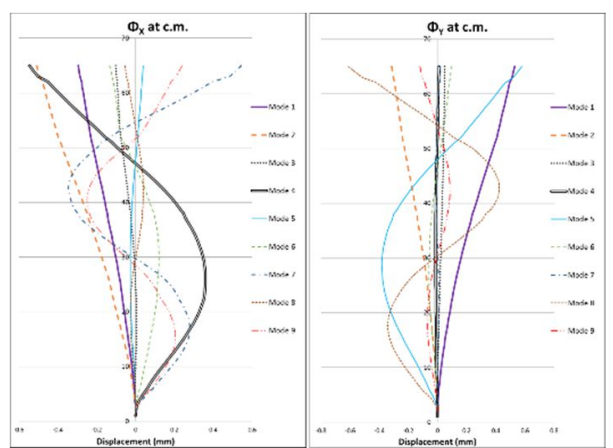

Fig 7. Mode shapes for X-dir component (left) and Y-dir component (right)

Components with deformation-controlled actions are utilized to achieve controlled and stable inelastic behavior of the building. For this building, the energydissipating mechanism is targeted to occur within the coupling beams and through flexural yielding of the shear walls, concentrated at the base fixity level (Ground floor) and at outrigger levels (figure 8).

The nominal capacity of components with forcecontrolled actions must be designed to withstand the maximum force that may occur in order to avoid brittle failure of primary structural members and to ensure desirable inelastic behavior can be achieved. For this building, shear action in core-wall and columns and axial action in columns are considered as forcecontrolled actions.

\section{Nonlinear modeling}

A 3-D computer analysis model is developed using ETABS 2015. Nonlinear modeling of components anticipated to reach plastic range is modeled in accordance with ATC 72-1.

Coupling beams are modeled using a rigid shear link based on the backbone curve for shear hinge component per ATC 72-1 (figure 8).

Shear-walls are modeled as fibers using nonlinear layered shell components available in ETABS 2015. The illustration of the fiber model is shown in figure 8 . The stress-strain curve for confined concrete material is modeled based on Mander. The stress-strain curve for steel reinforcement is modeled in accordance with ASTM A615.

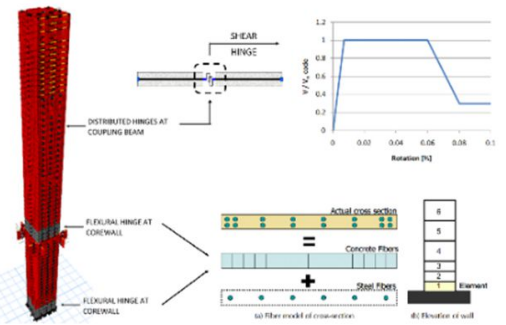

Fig 8. Target yielding mechanism for Indonesia-1 North Tower, including flexural hinge for the core-wall and shear hinge for the coupling beams. [source ATC-72-1]

\section{Acceptance criteria}

In principle, acceptance criteria used to evaluate the adequacy of structural elements at the performance point can be differentiated between deformationcontrolled and force-controlled actions. For deformation-controlled actions, the applicable criteria are deformation limits based on ATC 72-1. For forcecontrolled actions, the criteria are met by ensuring the capacity of component for the particular structural action of interest exceeds the internal force demand at performance point. Table 2 provides a summary of the acceptance criteria used to achieve Collapse Prevention at $\mathrm{MCE}_{\mathrm{R}}$ level.

Table 2. MPA Acceptance Criteria

Item Value

\begin{tabular}{|c|c|}
\hline Story Drift & $3 \%$ under $\mathrm{MCE}$ \\
\hline $\begin{array}{l}\text { Coupling Beam (Frame } \\
\text { Type) Rotation }\end{array}$ & $\begin{array}{l}\text { 0.04-radian } \\
\text { limit }\end{array}$ \\
\hline $\begin{array}{l}\text { Coupling Beam } \\
\text { (Diagonal) Rotation }\end{array}$ & $\begin{array}{l}\text { 0.06-radian } \\
\text { limit }\end{array}$ \\
\hline $\begin{array}{l}\text { Core Wall Reinforcement } \\
\text { Axial Strain }\end{array}$ & $\begin{array}{l}\text { Rebar tensile strain }= \\
0.05 \text { in tension and } 0.02 \\
\text { in compression }\end{array}$ \\
\hline $\begin{array}{l}\text { Core Wall Concrete Axial } \\
\text { Strain }\end{array}$ & $\begin{array}{l}\text { Fully Confined Concrete } \\
\text { Compression Strain = } \\
0.015\end{array}$ \\
\hline Core Wall Shear & $\begin{array}{l}\text { Verification performed } \\
\text { for elastic behavior }\end{array}$ \\
\hline $\begin{array}{l}\text { Outrigger Column Axial } \\
\text { and Shear }\end{array}$ & $\begin{array}{l}\text { Verification performed } \\
\text { for elastic behavior }\end{array}$ \\
\hline
\end{tabular}

\section{Earthquake demand level \& performance point for MPA}

One of the key components in PBSD evaluation using nonlinear static procedure is the estimation of maximum response for an inelastic system, represented by peak roof displacement. This parameter is commonly labeled as target displacement in the displacement modification method, and performance point in equivalent linearization method determined based on the applicable earthquake demand level. The structural state, including deformation and internal forces, at this performance point, is used to evaluate structural performance against the applicable acceptance criteria.

For Indonesia-1 North tower, the procedure used to determine performance point at $\mathrm{MCE}_{\mathrm{R}}$ level is the FEMA440 Linearization method, considered to have the best accuracy compared to other alternative procedures (Powell, 2006). In principle, the linearization process is conducted within Acceleration-Displacement Response 
Spectrum (ADRS) format for a particular mode of interest by determining the secant period, $\mathrm{T}_{\mathrm{sec}}$, based on the associated modal capacity curve. The demand spectrum curve, modified accordingly to reflect effective damping, is plotted against the capacity curve. The intersection between the two curves is defined as the performance point, which is used to estimate maximum structural response. This process is iterative since the secant period, and effective damping are both computed as a function of a single variable, namely ductility $\mu$ (figure 9).

\section{Pbsd evaluation using MPA procedure}

FEMA440 Linearization procedure was conducted for 20 modes where $90 \%$ of mass participation has been achieved. The structural response for each mode was combined using the Complete Quadratic Combination (CQC) rule, which is the more accurate option compared to Square Root Sum Square (SRSS) rule, particularly for structures with closely-spaced periods. The correlation coefficient for CQC was determined based on the Der Kiureghian equation.

The performance point for the first three pairs of translation modes is shown on the pushover curved in the ADRS format (figure 10). Mode 3 and 6 are not shown since they are torsionally-dominant modes resulting in negligible lateral deformation.

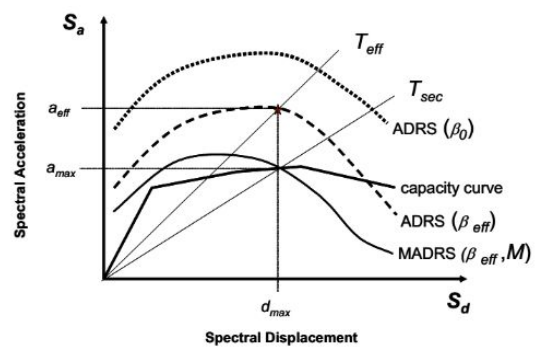

Fig 9. Acceleration Displacement Response Spectrum (ADRS) plot based on FEMA 440 Linearization method [source: FEMA440]

Structural actions classified as deformationcontrolled actions, including shear hinge/rotation of coupling beams and core-wall strain (axial compression in concrete and axial compression \& tension in steel reinforcement), were evaluated and found to satisfy the applicable acceptance criteria (figure 11 and 12).

Components with structural actions classified as force-controlled, including shear on core-wall and axial on columns, were designed to withstand the maximum force estimated to occur on those components.

Based on MPA evaluation, the structural performance of the Indonesia-1 North tower can be summarized as follows:
- The plastic distribution of coupling beam hinges has occurred relatively uniform throughout the height of the tower (figure 11).

- Flexural yielding of the core-wall has occurred at the base and at the outrigger levels (figure 12).

- Global drift and inter-story drift are still far within the acceptance criteria limit, even less than $1 \%$ (figure $14 \& 15$ ).

\section{MPA results}

The MPA results are compared against other procedures, including RSA code, NSP fundamental mode, and NLRHA. The structural response subject to comparison includes story shear, displacement, and inter-story drift, which are assessed to verify the level of accuracy of the MPA results (figure 13, 14 \& 15).

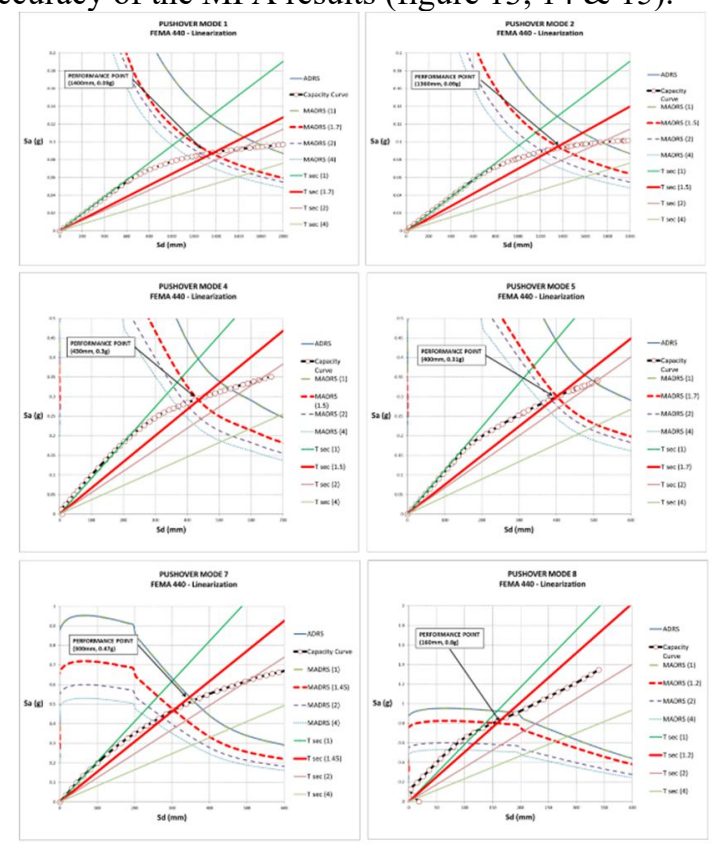

Fig 10. Pushover curve in ADRS format to determine performance point for the first three translational modes

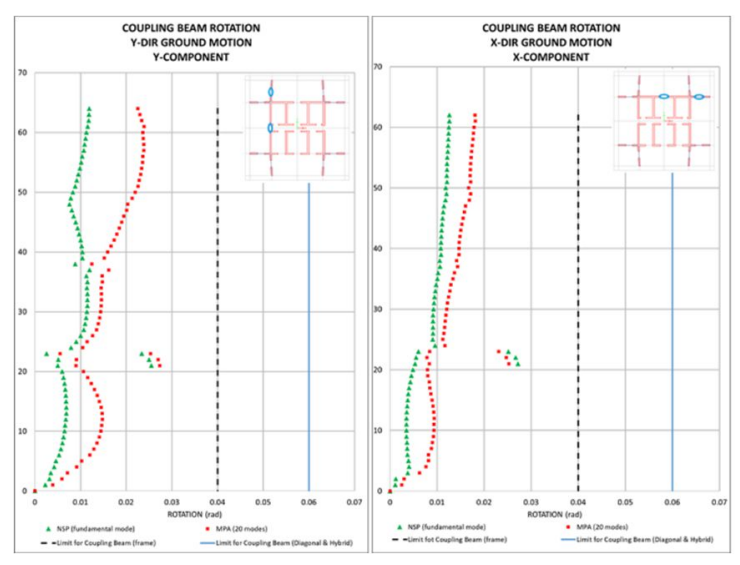

Fig 11. Coupling beam rotation (MPA) 


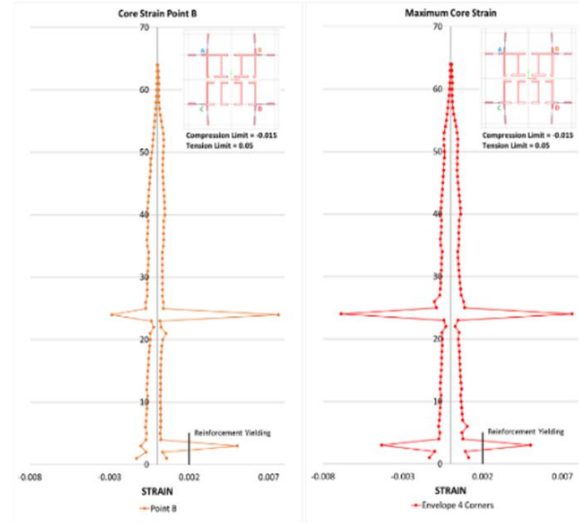

Fig 12. Core-wall strain (MPA)

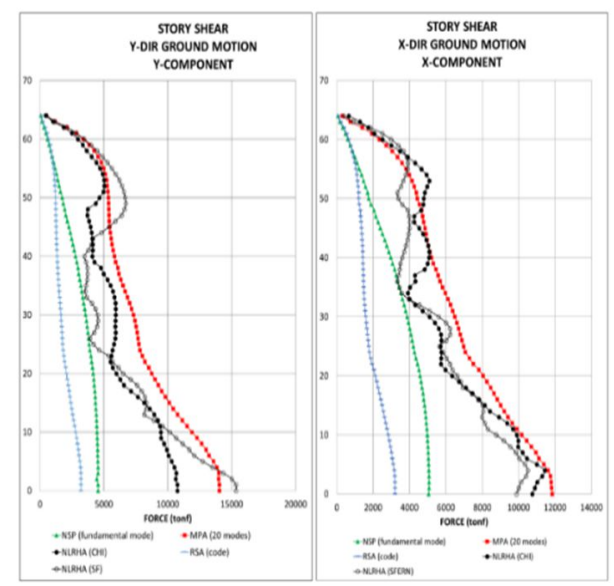

Fig 13. Story shear for $Y$ component (left) \& X component (right)

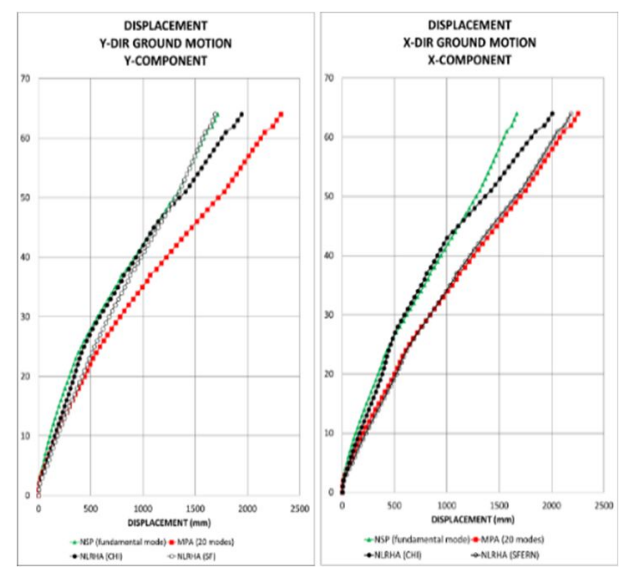

Fig 14. Displacement for $Y$ component (left) \& X component (right)

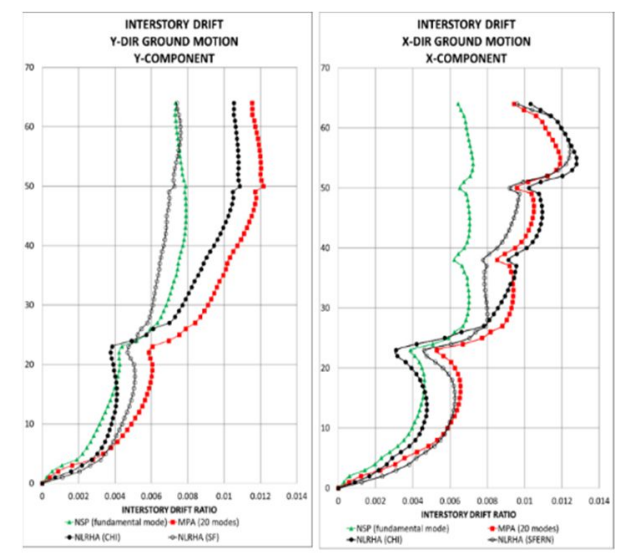

Fig 15. Interstory drift ratio for $Y$ component (left) \& $X$ component (right)

\section{Conclusion}

As previously discussed, NLRHA is currently the most accurate procedure in estimating the structural response of tall buildings. Commonly, the average of a suite of record (7 pairs in ASCE 7-10 or 11 pairs in ASCE 7-16) is used to provide a structural response estimate that can also capture record-to-record variability. For comparison purposes, a small number (2) of ground motion pairs are used as the benchmark, which is found to be useful in observing the level of accuracy between analysis procedures.

Based on comparison of various structural response (figure $10-12$ ), it can be observed that the MPA results reasonably match closely with the NLRHA results, while the other procedures, including RSA linear elastic code approach and NSP based on fundamental mode only, provided estimates that are far below NLRHA results.

\section{References}

1. ASCE 7-10, Minimum Design Loads for Buildings and Other Structures

2. FEMA 440: Improvement of Nonlinear Static Seismic Analysis Procedures, ATC

3. Technical Proposal for Indonesia-1: CCSED and CCEED.

4. PEER-TBI: Guidelines for Performance-Based Seismic Design of Tall Buildings (2010)

5. SNI 1726:2012 Tatacara Perencanaan Ketahanan Gempa untuk Struktur Bangunan Gedung dan Non-gedung, BSN (2012). 